\title{
PREVALENCE, SEVERITY, DISTRIBUTION AND RISK INDICATORS OF GINGIVAL RECESSION IN QENA GOVERNORATE (UPPER EGYPT): AN EPIDEMIOLOGICAL STUDY
}

\author{
Ahmed G. Elafyouny ${ }^{1 *}$, Mohamed Assaadawy ${ }^{2}$, Hisham Abozaid ${ }^{3}$, AbdelFattah.M.Amer ${ }^{4}$
}

\begin{abstract}
Objective: The present study estimated the prevalence of gingival recession (its severity and distribution) and assessed the association of potential risk indicators with the occurrence of gingival recession in Qena governorate, Egypt. Subject and methods: A representative sample of 1959 patients aged from 18 -90 years old (984 males and 975 females) from different areas in Qena governorate, Egypt were examined. A descriptive questionnaire was prepared for the examinations and full personal data were recorded. Results: The prevalence of gingival recession was 32.8\%; Class I recession was (24.2\%) followed by Classes II, III and IV (7.2, 1.3 and $0.1 \%)$ respectively. The most affected quadrants were the lower left quadrant while the least affected quadrant was the upper right quadrant. The most affected teeth were lower anterior teeth while the least commonly affected teeth were lower right posterior teeth. Conclusion: Prevalence of gingival recession showed more frequently in males than in females. Gingival recession was found to be more common in mandibular arch than maxillary. Lower anterior teeth than posterior ones and Left side of the arch was more commonly affected. This is a preliminary basis toward establishing a complete epidemiological study regarding the prevalence, severity as well as manifestations of oral diseases in Egypt. Hopefully, this help toward planning effective, preventive as well as therapeutic measures in this regard.
\end{abstract}

KEY WORDS: Prevalence, severity, distribution and risk indicators of gingival recession

\section{INTRODUCTION}

Gingival recession (GR) manifested clinically by an apical displacement of gingival tissues leading to root surface exposure, which often causes poor esthetics. It is characterized by the displacement of the gingival margin apically from Cemento-enamel junction $(\mathrm{CEJ})^{(1)}$. GR has a multifactorial etiology and is always result of more than one factor acting together ${ }^{(2,3)}$. In this respect, tobacco smoking has been considered risk factors for development of destructive forms of periodontal disease as well as associated with $\mathrm{GR}^{(2)}$.

It has been documented that ${ }^{(4,5)} \mathrm{GR}$ was associated with a high level of dental plaque. Similarly, a study

1. Masters Candidate, Department of Oral Medicine, Periodontology, Diagnosis; Oral Radiology, Faculty of Dental Medicine, October 6 University

2. Assistant Professor, Periodontology, Oral medicine, Diagnosis and Oral Radiology, Faculty of Dental Medicine, Al-Azhar Boys Cairo

3. Lecturer, Periodontology, Oral medicine, Diagnosis and Oral Radiology, Faculty of Dental Medicine, Al-Azhar Boys Cairo.

4. Professor, Periodontology, Oral medicine, Diagnosis and Oral Radiology, Faculty of Dental Medicine, Al-Azhar Boys Cairo.

-Corresponding author: medokon@hotmail.com 
observed that the plaque index (PI) was associated with the extent of GR ${ }^{(6)}$, although, another study recorded a negative correlation between dental plaque on the buccal tooth aspect and $\mathrm{GR}^{(7)}$, which may be associated with dentine hypersensitivity, root caries, abrasion and/or cervical wear, erosion because of exposure of root surface to the oral environment and an increase in accumulation of dental plaque ${ }^{(8)}$. The presence and extent of gingival recession reported to be increased with age ${ }^{(9)}$.

Miller in 1985 proposed a classification for gingival recession which is the most widely used today ${ }^{(10)}$. In 2010 Mahajan modified Miller's classification of GR that based on the severity of soft and hard tissue loss in the inter-proximal area. Based on the class of recession prognosis was suggested, Class I and Class II with thin gingival profile has good prognosis, Class III with thick gingival profile has fair prognosis and Class III and Class IV with thin gingival profile has poor Prognosis ${ }^{(11)}$. Despite the frequent observation in adult subjects, the occurrence and severity of the gingival recession presents considerable differences between study populations. A new classification of gingival recession with reference to interdental clinical attachment loss has been advised ${ }^{(12)}$; Recession Type 1 (RT1): Gingival recession with no loss of interproximal attachment. Interproximal CEJ is clinically not detectable at both mesial and distal aspects of the tooth, Recession Type 2 (RT2): Gingival recession associated with loss of interproximal attachment. The amount of interproximal attachment loss (measured from the interproximal CEJ to the depth of the interproximal sulcus/pocket) is less than or equal to the buccal attachment loss (measured from the buccal CEJ to the apical end of the buccal sulcus/pocket), Recession Type 3 (RT3): Gingival recession associated with loss of interproximal attachment. The amount of interproximal attachment loss (measured from the interproximal CEJ to the apical end of the sulcus/ pocket) is higher than the buccal attachment loss (measured from the buccal CEJ to the apical end of the buccal sulcus/pocket).

Epidemiology is a useful means of establishing a need for treatment or for preventive intervention. A number of studies have been carried out on the prevalence and occurrence of gingival recession among different populations ${ }^{(13-15)}$. A prevalence of $90 \%$ was reported in older institutionalized subjects ${ }^{(16)}, 58 \%$ in a US study ${ }^{(17)}$ and in Germany, gingival recession occurred in $76-87 \%$ of middleaged subjects ${ }^{(18)}$. Therefore, it is important to collect detailed information, to assess the tendency and epidemiology of this condition, identify the etiological factors and establish preventive measures.

In fact, regarding to Egypt it seems to be of hard task to find clear information that will aid in giving figures in that regarded. In view of this knowledge, present study was designed to estimate the prevalence, severity, distribution of gingival recession and to assess the association of potential risk indicators with the occurrence of gingival recession in one of Egyptian governorates (Qena governorate).

\section{SUBJECTS AND METHODS}

A representative sample of 1959 patients were selected to be examined aged from 18 -90 years old. These subjects consisted of 984 males and 975 females in different areas in Qena governorate, Egypt according to the data below (Table 1). These subjects were subjected to full clinical examination of oral and para-oral structure by some examiners. Then the individuals fill in an appropriate questionnaire regarding several aspects of their medicine and dental history and they also are being examined. 
TABLE (1) Demographic data of included sample.

\begin{tabular}{|c|c|c|c|c|c|c|}
\hline Area & $\begin{array}{c}\text { Males } \\
\text { above } \\
18 \text { years }\end{array}$ & $\begin{array}{c}\text { Females } \\
\text { above } \\
18 \text { years }\end{array}$ & $\begin{array}{l}\text { Total population } \\
\text { above } 18 \text { years }\end{array}$ & $\begin{array}{c}\text { Males } \\
\text { Estimated } \\
\text { Sample Number }\end{array}$ & $\begin{array}{c}\text { Females } \\
\text { Estimated } \\
\text { Sample Number }\end{array}$ & $\begin{array}{c}\text { Total Estimated } \\
\text { Sample }\end{array}$ \\
\hline Abotesht & 129109 & 138174 & 546712 & 129 & 138 & 267 \\
\hline Farshout & 51005 & 54118 & 211084 & 51 & 54 & 105 \\
\hline NagaHamamady & 174407 & 181828 & 593724 & 174 & 182 & 356 \\
\hline Alwaqf & 27477 & 26932 & 90682 & 27 & 27 & 54 \\
\hline Qena & 212565 & 199059 & 685708 & 213 & 201 & 414 \\
\hline Qoft & 53552 & 52936 & 177479 & 54 & 53 & 107 \\
\hline Qous & 144365 & 144469 & 481391 & 144 & 144 & 288 \\
\hline Naqadah & 47342 & 51871 & 184294 & 47 & 52 & 99 \\
\hline Deshna & 145162 & 123799 & 448268 & 145 & 124 & 269 \\
\hline TOTAL & 973186 & 984984 & 1958170 & 984 & 975 & 1959 \\
\hline
\end{tabular}

\section{Questionnaire :}

The descriptive questionnaire was prepared for the examinations and full personal data were recorded. The questionnaire included questions concerning age, socio-economic level, systemic and oral health status, smoking habits, information related to toothbrush type and tooth-brushing technique and frequency of each patient. Toothbrushing frequency should be scored as follows: 1: less than once a day; 2 : once a day and 3: twice a day or more. After the questionnaire had been completed, each patient will receive a full mouth examination for assessing gingival recession (site, severity, and distribution), dental plaque and calculus, frenum attachment, and presence of traumatic tooth-brushing. Every subject will be examined in a dental chair using dental chair light, mouth mirror, explorer, periodontal probe; entire mouth will be examined in a uniform pattern.

Presence of gingival recession were recorded according the criteria of Miller's classification $(1985)^{[10]}$. This study was carried out from May to December 2019.

\section{Ethical concern:}

All included subjects were informed about the nature of the research and they asked to give a written consent to participate in the study. A detailed verbal and written explanation of the purpose of the study was provided. The subjects were advised that the diagnostic phase and treatment protocol would not adversely affect the outcome of treatment.

\section{RESULTS}

\section{Gingival Recession}

The prevalence of recession was $32.8 \%$; Class I recession was $(24.2 \%)$ followed by Classes II, III and IV $(7.2,1.3$ and $0.1 \%$, respectively). The most affected quadrants were the lower left and right quadrants $(83,82.2 \%$, respectively) where recession affected considerably more teeth in anterior area than posterior while the least affected quadrant was the upper right quadrant (52.8\%). The most affected teeth were lower anterior teeth $(76.9 \%)$ followed by upper left posterior teeth (46\%) then upper right posterior teeth $(45.3 \%)$. The least commonly affected teeth were lower right posterior teeth (29.9\%). These data are presented in Table 2 and Figure 1. 
TABLE (2) Frequencies (n) and percentages (\%) for gingival recession findings among the study participants

\begin{tabular}{|c|c|c|}
\hline Gingival recession & $\mathrm{N}$ & $\%$ \\
\hline Overall prevalence of recession & $642 / 1959$ & 32.8 \\
\hline \multicolumn{3}{|c|}{ Gingival recession classification } \\
\hline Class I & $475 / 1959$ & 24.2 \\
\hline Class II & $141 / 1959$ & 7.2 \\
\hline Class III & $25 / 1959$ & 1.3 \\
\hline Class IV & $1 / 1959$ & 0.1 \\
\hline \multicolumn{3}{|c|}{ Affected quadrants } \\
\hline Upper right & $339 / 642$ & 52.8 \\
\hline Upper left & $342 / 642$ & 53.3 \\
\hline Lower left & $533 / 642$ & 83 \\
\hline Lower right & $528 / 642$ & 82.2 \\
\hline \multicolumn{3}{|c|}{ Affected teeth } \\
\hline Upper anterior teeth & $207 / 642$ & 32.2 \\
\hline Lower anterior teeth & $494 / 642$ & 76.9 \\
\hline Upper right posterior teeth & $291 / 642$ & 45.3 \\
\hline Upper left posterior teeth & $295 / 642$ & 46 \\
\hline Lower right posterior teeth & $192 / 642$ & 29.9 \\
\hline Lower left posterior teeth & $213 / 642$ & 33.2 \\
\hline
\end{tabular}

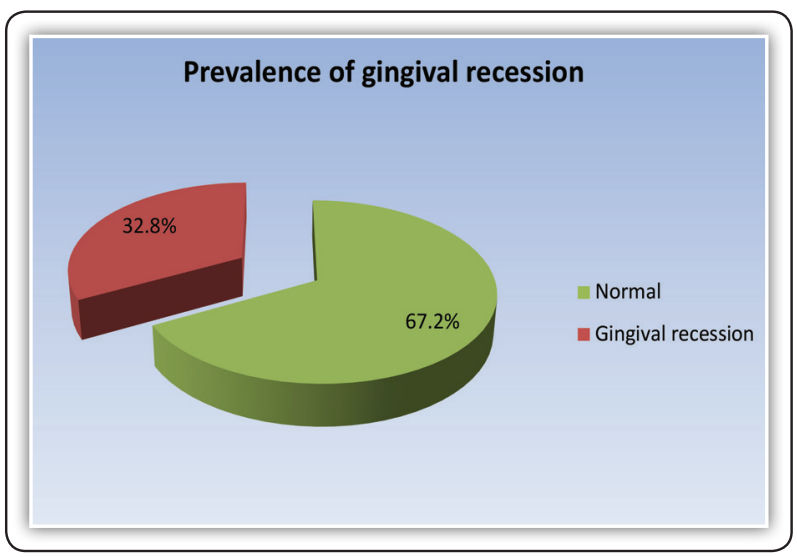

FIG (1) Pie chart representing prevalence of gingival recession $(\mathrm{n}=1959)$

\section{Tooth mobility}

Prevalence of tooth mobility was $10.6 \%$; Grades I and II showed almost the same prevalence (4.9 and $4.8 \%$, respectively) while Grade III was only found in $0.9 \%$ of the participants. The most affected quadrants were the lower left and right quadrants $(60.1,58.7 \%$, respectively) while the least affected quadrant was the upper right quadrant (33.7\%). The most affected teeth were lower anterior teeth $(42.8 \%)$ followed by lower left posterior teeth $(37.5 \%)$ then lower right posterior teeth $(33.7 \%)$. The least commonly affected teeth were upper anterior teeth (18.3\%) (Table 3 and Fig. 2).

TABLE (3) Frequencies (n) and percentages (\%) for tooth mobility findings among the study participants

\begin{tabular}{|c|c|c|}
\hline Tooth mobility & $\mathrm{N}$ & $\%$ \\
\hline Overall prevalence of tooth mobility & 208/1959 & 10.6 \\
\hline \multicolumn{3}{|c|}{ Tooth mobility grades } \\
\hline Grade I & $96 / 1959$ & 4.9 \\
\hline Grade II & $94 / 1959$ & 4.8 \\
\hline Grade III & $18 / 1959$ & 0.9 \\
\hline \multicolumn{3}{|c|}{ Affected quadrants } \\
\hline Upper right & $70 / 208$ & 33.7 \\
\hline Upper left & $72 / 208$ & 34.6 \\
\hline Lower left & $125 / 208$ & 60.1 \\
\hline Lower right & $122 / 208$ & 58.7 \\
\hline \multicolumn{3}{|c|}{ Affected teeth } \\
\hline Upper anterior teeth & $38 / 208$ & 18.3 \\
\hline Lower anterior teeth & $89 / 208$ & 42.8 \\
\hline Upper right posterior teeth & $60 / 208$ & 28.8 \\
\hline Upper left posterior teeth & $65 / 208$ & 31.3 \\
\hline Lower right posterior teeth & $70 / 208$ & 33.7 \\
\hline Lower left posterior teeth & $78 / 208$ & 37.5 \\
\hline
\end{tabular}




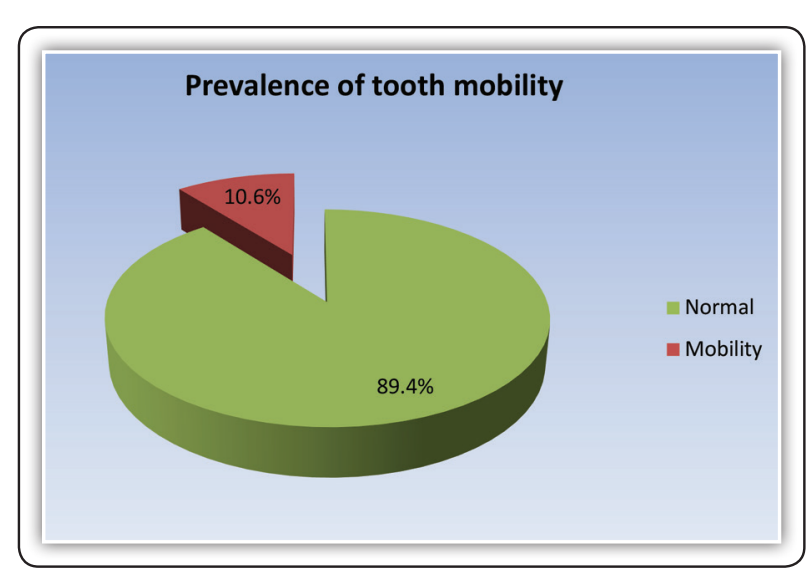

FIG (2) Pie chart representing prevalence of tooth mobility ( $\mathrm{n}=1959)$

\section{Gingival bleeding}

Prevalence of gingival bleeding was $32.1 \%$ (Fig. 3). Bleeding of the gingiva was measured by probing positively or negatively. But, it wasn't graded or tabulated.

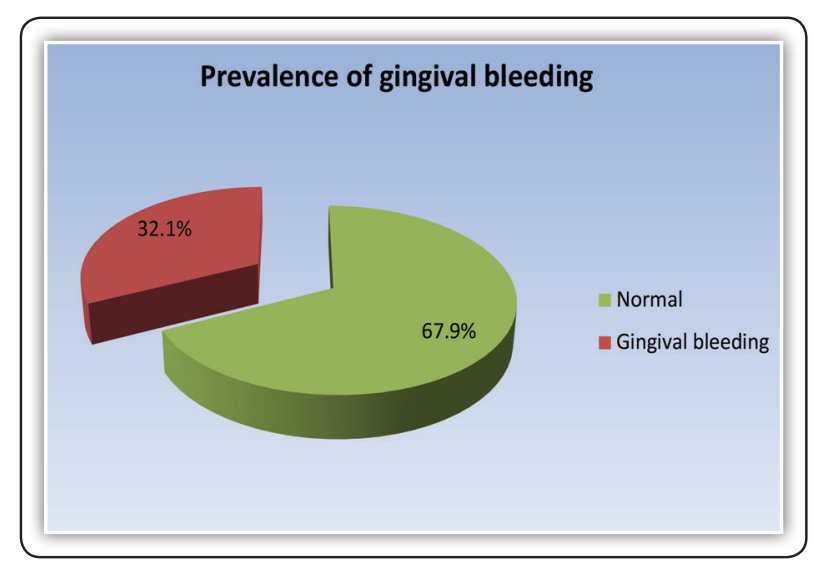

FIG (3) Pie chart representing prevalence of ginigval bleeding $(\mathrm{n}=1959)$

\section{Geographic area and gingival recession:}

There was a statistically significant association between location and gingival recessions ( $P$-value $<0.001$, Effect size $=0.128)$. Qena showed the highest prevalence of gingival recession (25.9\%) followed by Nagaa Hamadi (20.4\%) then Qous
$(13.7 \%)$. The least prevalence of gingival recession was found in Farshout (5.1\%), Naqada (4.8\%) then Elwaqf (3.3\%), Fig. 4 representing these data.

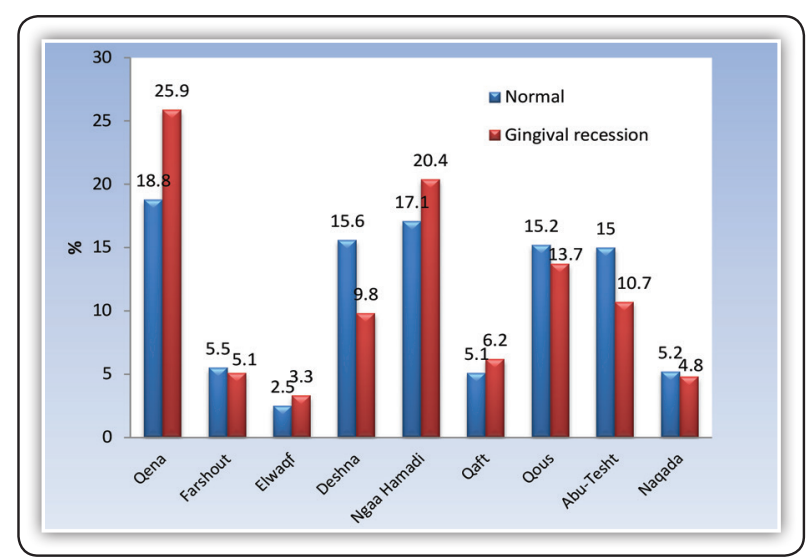

FIG (4) Bar chart representing the percentage distribution of gingival recession among different geographic areas

\section{Gender and gingival recession:}

There was a statistically significant association between gender and gingival recessions ( $P$-value $=0.003$, Effect size $=1.210)$. Males showed statistically significantly higher prevalence of gingival recession than females. Males are 1.21 folds prone to gingival recession than females, Fig. 5 showing these data.

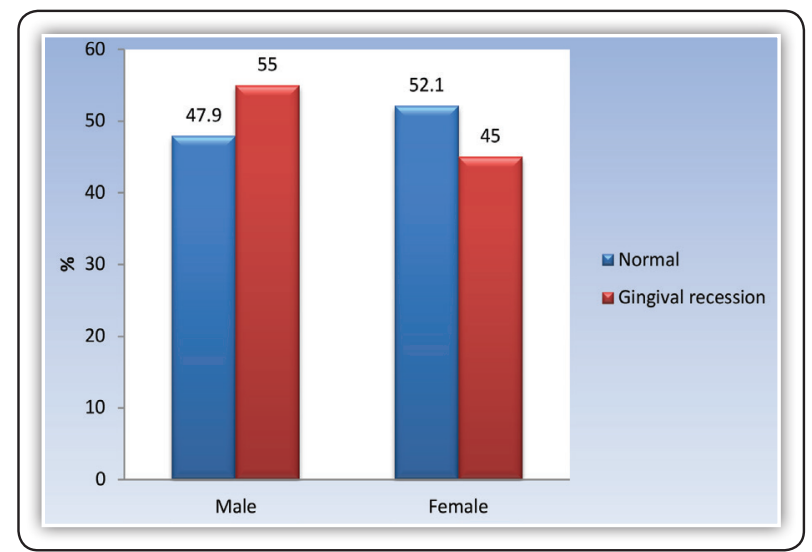

FIG (5) Bar chart representing the percentage distribution of gingival recession among males and females 


\section{DISCUSSION}

Epidemiology is a useful means toward establishing a effective and useful treatment or for planning preventive measures. It often deals with correlations between two or more findings. However, correlations are not a means of showing cause and effect relationship but only a means of showing a relationship.

Gingival Recession (GR) is a common and undesirable condition, concerns individuals of all ages throughout the world and its presence is disturbing for patients regarding esthetic, psychological as well as functional problems.

The overall prevalence of gingival recession in the present study showed a value of $32.8 \%$, as Class I recession was the most followed by Classes II, III and IV respectively. The mandible was most affected than the maxilla. These findings were in agreement with the previous studies ${ }^{(19-2)}$, Areas with deficient keratinized mucosa have been demonstrated to be more susceptible to gingival recession, due to less amount of connective tissue available at this area. Hence, localized inflammatory reactions which are triggered by different processes that affect the entire extension of the tissue, ultimately leading to gingival recession.

It was evident from the obtained results that, the most affected quadrants were the lower left and right quadrants and most affected teeth were lower anterior teeth, these results were consistent with another study ${ }^{(24)}$ reported that gingival recession was more common in mandibular anterior teeth. However, few other studies showed that gingival recession was more in maxillary first molar ${ }^{(14,25)}$ .This finding may attributed to the angulations of the root in the bone, which can influence recession incidence observed in maxillary molars area.

The gingival recession was more on the left side compared to right side, which can be attributed to the more vigorous tooth brushing on this side by the right handed patients. Additionally, most of patients use their right side in eat which, lead to self cleaning process by the movement of foods, while more accumulation of debris and calculus can occur on the less used side, i.e: the left side .

The present study sample was 1959 people [984 males (50.2\%),975 females (49.8\%)], ranging in age between 18 and 88 years old [mean (SD) values for age were 37.1 (13.4)]. The prevalence of GR was overall $32.8 \%$, Males showed statistically significantly higher prevalence of gingival recession than females (55\% in males and $45 \%$ in females) i.e. Males were 1.21 folds prone to gingival recession than females. Studies showed that GR prevalence between $22.5 \%$ and $27.7 \%(26,27)$. Similar findings regarding the distribution of GR by gender were found in previous reports ${ }^{(6,18)}$, although other studies recorded prevalence range of $50 \%$ and more ${ }^{(4,14,18)}$. Clearly, most of the studies showed that the gingival recession prevalence with higher rates in males than in females. Only one study ${ }^{(28)}$ observed that $31.7 \%$ of females and $24.3 \%$ of males showed GR. This finding may be attributed to the fact that females can be motivated more regarding the oral hygiene practices and, thus, brush their teeth more frequently than males.

The results of this study showed statistically significant association between, geographic areas and gingival recessions, as Qena showed the highest prevalence of gingival recession (25.9\%), while least prevalence of gingival recession was found in Elwaqf (3.3\%).

Significantly higher frequency of GR was observed in smokers than in non-smokers. This finding is in accordance with those of previous studies, in which tobacco smoking was regarded as one of the main risk factors for the development of destructive forms of periodontal disease ${ }^{(29)}$, while a combination of smoking and supragingival calculus was associated with localized and generalized gingival recession ${ }^{(3,4,30-32)}$. However, this is not always the case as Muller et $\mathrm{al}^{(33)}$ revealed that smoking status was not identified as a risk factor 
for the development of GR, and similar studies have suggested a negative impact on GR and periodontal health from tobacco ${ }^{(29,34,35)}$. This controversy awaits further clarification through performing other studies on larger samples with clear inclusion and exclusion criteria.

It should be emphasized that, the vast majority of information in field epidemiology of various dental/oral disease comes from studies performed in populations outside the Arab world. This area of research seems to be deficient, as it will be a hard task to find clear, firm as well as reliable data from oral epidemiological studies performed in various Arabian countries. Hence, the present work was designed and performed toward establishing a source of data regarding the prevalence as well as severity of periodontal disease in a part of Egypt.

\section{REFERENCES}

1. Kassab M, Cohen R. The etiology and prevalence of gingival recession. J Am Dent Assoc 2003; 134:220-225.

2. Tugnait A, Clerehugh V. Gingival recession - its significance and management. J Dent 2001; 29: 381-94.

3. Susin C, Haas A, Opperman R, Haugejorden O, Albandar J. Gingival recession. J Periodontol 2004; 75: 1377-86.

4. Toker H, Ozdemir H. Gingival recession: epidemiology and risk indicators in a university dental hospital in Turkey. Int J Dent Hyg 2009; 7: 115-20

5. Murray J. Gingival recession in tooth types in high fluoride and low fluoride areas. J Periodontol Res 2006; 8: 243-51.

6. Sarfati A, Bourgeois D, Katsahian S, Mora F, Bouchard P. Risk assessment for buccal gingival recession defects in an adult population. J Periodontol 2010; 81: 1419-25.

7. Roberts-Harry E, Clerehugh V. Sub-gingival calculus: where are we now? A comparative review.J Dent 2000; 28: 93-102.

8. Mathur A, Jain M, Jain K, Samar M, Goutham B, Swamy P, et al.Gingival recession in school kids aged 10-15 years in Udaipur, India. J Indian Soc. Periodontol 2009;13:16-20.

9. Marini M, Greghi L, Passanezi E, Sant'Ana A. Gingival recession:prevalence, extension and severity in adults. J Appl Oral Sci. 2004; 12:250-5.

10. Miller P. A classification of marginal tissue recession. Int $\mathbf{J}$ Periodontics Restorative Dent. 1985; 5:8-13.
11. Mahajan A. Mahajan's modification of Miller's classification for gingival recession. Dent. Hypotheses 2010;1: 45-50.

12. Jepsen S, Caton JG, et al. Periodontal manifestations of systemic diseases and developmental and acquired conditions: Consensus report of workgroup 3 of the 2017 World Workshop on the Classification of Periodontal and Peri-Implant Diseases and Conditions. J Clin Periodontol. 2018;45(Suppl 20):S219 S229.

13. Fernando S, Ricardo SA, Juliana J, Marsia Malt. Estimates and multivariable risk assessment of gingival recession in the population of adults from Porto Alegre, Brazil. J. Periodontol. 2014;11:1098-1107.

14. Nikolaos A Chrysanthakopoulos . Gingival recession : prevalence and risk indicators among young greek adults. J clin Periodontol . 2014;63:220-243.

15. J Seong, D Bartlett, RG Newcombe, N Hellin. Prevalence of gingival recession and study of associated related factors in young UK adults. J. Dent. 2018;76:58-67.

16. Sarpangla M, Suryanarayan M, Shanker R, Devasya A. Etiology and occurrence of gingival recession - An epidemiological study. J Indian Soc Periodontol. 2015;19:560-671.

17. Nibali L, Zavattini A, Nagata K, Di Iorio A, Lin G, Needleman I, Donos N. Tooth loss in molars with and without furcation involvement -a systematic review and meta-analysis. J ClinPeriodontol, 2016; 43: 156-66.

18. Susin C, DallaVecchia C, Oppermann R, Haugejorden O, Albandar J. Periodontal attachment loss in an urbanpopulation of Brazilian adults: Effect of demographic,behavioral and environmental risk indicators. J Periodontol. 2004; 75:1033-41.

19. Dodwad V. Etiology and severity of gingival recession among young individuals in Belgaum district in India.Annal Dent Univ Malaya 2001;8:1-6.

20. Vehkalahti M. Occurrence of gingival recession in adults. J Periodontol 1989;60:599-603.

21. Almeida AL, Madeira LC, Freitas KC, Greghi SL, Pegoraro LF. Cross-sectional evaluation of the presence of gingival recession in individuals with cleft lip and palate. $\mathrm{J}$ Periodontol 2007;78:29-36.

22. O'Leary TJ, Drake RB, Jividen GF, Allen MF. The incidence of recession in young males. Relationship to gingival and plaque scores. J Periodontol 1968;6:109-20.

23. Manchala SR, Vandana KL, Mandalapu NB, Mannem S, Dwarakanath CD. Epidemiology of gingival recession and risk indicators in dental hospital population of Bhimavaram. J Int Soc Prev Community Dent 2012;2:69-74. 
24. Akpata ES, Jackson D. The prevalence and distribution of gingivitis and gingival recession in children and young adults in Lagos, Nigeria. J Periodontol 1979;50:79-83.

25. Gillette WB, Van House RL. Ill effects of improper oral hygiene procedure. J Am Dent Assoc 1980;101:476-80.

26. Sakshi Khattar et al. Gingival Recession: Prevalence, Severity and Possible Etiological Factors in the Out Patients of Subharti Dental College and Hospital, Meerut- An Epidemiological Study.Sch. J. Dent. Sci., 2015; 2:343-8.

27. Marini MG, Greghi LA, Passanezi E, Sant'Ana ACP. Gingival recession:prevalence, extension and severity in adults. J Appl Oral Sci. 2004;12:250-5.

28. Kozlowska M, Wawrzyn-Sobczak K, Karczewski JK, Stokowska W. The oral cavity hygiene as the basic element of the gingival recession prophylaxis. Rocz AkadMedyc Bial Mstok. 2005;50:234-7.

29. Axelsson P, Paulander J, Lindhe J. Relationship between smoking and dental status in 35-, 50-, 65- and 75 year old individuals. J Clin Periodontol 1998; 25: 297-305.
30. Roman A, Louise F, M'barek R, Brunel- Trotebas S. Gingival recessions: epidemiologic ,etiologic and therapeutic aspects. Intern Jour Dent Science 2009;7: 1.

31. Arowojolu MO. Gingival recession at the University College Hospital, Ibadan - prevalence and effect of some aetiological factors. Afr J Med Med Sci 2000; 29: 259-63.

32. Mumghamba EG, Honkala S, Honkala E, Manji KP. Gingival recession, oral hygiene and associated factors among Tanzanian women. East Afr Med J 2009; 86: 125-32.

33. Muller HP, Stadermann S, Heinecke A. Gingival recession in smokers and non-smokers with minimal periodontal disease. J Clin Periodontol 2002; 29: 129-36.

34. ergstrom J, Eliasson S, Dock J. Exposure to tobacco smoking and periodontal periodontal disease. J ClinPeriodontol 2009; 27: 61-8.

35. Serino G, Wennstr€om JL, Lindhe J, Eneroth L. The prevalence and distribution of gingival recession in subjects with a high standards of oral hygiene. J Clin Periodontol 1994; 21: 57-63. 